\title{
Flight Experiments on the Effects of Contamination on Electron Emission of Materials \\ JR Dennison, ${ }^{1}$ Joshua L. Hodges, ${ }^{2}$ Jeff Duce ${ }^{3}$ and Amberly Evans ${ }^{3}$ \\ Utah State University Physics Department, Logan, Utah, 84322
}

We report on a study of the effects of prolonged exposure to the space environment and of chargeenhanced contamination on the electron emission and resistivity of spacecraft materials. The State of Utah Space Environment \& Contamination Study (SUSpECS) was deployed on the International Space Station (ISS) in March 2008 onboard the MISSE-6 payload during STS-123. The Materials International Space Station Experiment (MISSE-6) program is designed to characterize the performance of candidate new space materials over the course of its 17 month exposure to the LEO environment, with a target return date of August 2009 on STS-127. Approximately 165 samples are mounted on three separate SUSpECS panels in the ram and wake sides on the ISS. They have been carefully chosen to provide needed information for different ongoing studies and a broad cross-section of prototypical materials used on the exteriors of spacecrafts. Design of the sample panels are detailed, including a three tiered configuration intended to provide variable atomic oxygen and ultraviolet radiation exposure. The methods used to simulate charge enhanced contamination by actively biasing samples to low positive and negative voltages are also described.

A primary emphasis of SUSPECS is the study of modifications to the electron emission resulting from exposure to the space plasma environment and to environmental contamination. There is presently little available data related to the effects of sample deterioration and contamination on emission properties for materials actually flown in space. Electron emission and transport properties of materials are key in determining the amount of charge build-up and the time for the charge to dissipate, as well as the likelihood of deleterious spacecraft charging effects. Such materials properties are essential parameters in modeling spacecraft charging with engineering tools like NASCAP-2K code. SUSpECS studies will test the validity of our predictions from ground-based studies that very thin layers of contamination can lead to severe charging effects under certain circumstance. Electron-, ion-, and photon-induced electron emission yield curves, crossover energies and emission spectra, as well as resistivity and dielectric strength, have been tested for most SUSpECS samples in their pristine conditions before flight. These measurements will be compared with post-flight measurements. Additional pre- and post-flight characterization measurements include optical and electron microscopy, reflection spectroscopy, emissivity and Auger electron spectroscopy.

\section{Introduction}

A cooperative, Utah-based project named SUSpECS (State of Utah Space Environment and Contamination Study) has developed a flight experiment to study the effects of prolonged exposure to the space environment and charge-enhanced contamination on spacecraft materials. Utah researchers from the Utah State University (USU) Materials Physics Group, the USU Space Dynamics Laboratory Contamination Control/Materials Chemistry Group, the ATK Space Systems Health Management Focus Group, and the USU Microgravity Research Team (MRT) have built sample trays for flight on the MISSE-6 (Materials International Space Station Experiment) mission sponsored by Air Force Office of Scientific Research (AFOSR). The MISSE program objective is to "characterize the performance of new prospective spacecraft materials when subjected to the synergistic effects of the space environment [1]. The SUSpECS sample panels include pertinent materials and coatings selected and characterized by each group member for a comprehensive study of the effects of the low Earth orbit (LEO) space environment and contamination on electrical, mechanical, and optical properties of materials related to several on-going projects of high relevance to manned space exploration and other long duration space missions.

\footnotetext{
${ }^{1}$ Professor, Physics Department, 4415 Old Main Hill Logan UT 84322, Senior Member.

${ }^{2}$ Graduate Researcher, Physics Department, 4415 Old Main Hill Logan UT 84322.

${ }^{3}$ Undergraduate Researcher, Physics Department, 4415 Old Main Hill Logan UT 84322.
} 
Sample material selections, conceptual design of the SUSPECS sample panels, and construction of the panels were completed during 2005 , led by student researchers from the USU Get-Away-Special Program. The SUSPECS sample panels were delivered to Boeing in spring 2006 for integration with the panels contributed by other industry, university, and government investigators. The sample panels were installed into two standard MISSE "suitcase" pallets that are powered and instrumented to record relevant space environmental parameters during the on-orbit exposure. The integrated payload was delivered to NASA Langley Research Center in summer 2006. The Shuttle flight STS-123 transported MISSE-6 to the ISS and deployed it on the ISS "back pourch" in March 2008. Figure 1 shows MISSE-6 mounted on ISS. MISSE-6 is scheduled for retrieval by STS-127 in August 2009, with return after $\sim 17$ months exposure in the LEO environment. After retrieval, sample panels will be returned to the SUSPECS team for post-flight analyses.

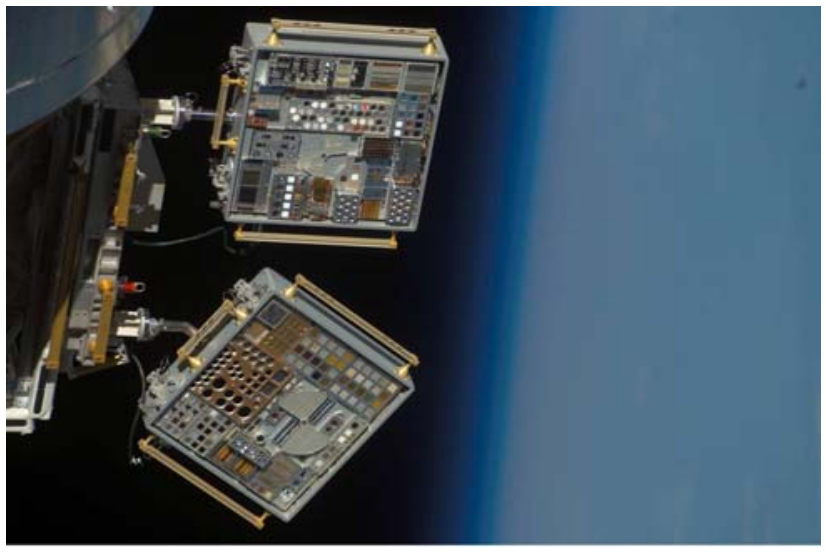

Figure 1. MISSE 6 exposed to the space environment. The SUSpECS double stack can be seen in the bottom center of the lower case. The picture was taken on the fifth EVA, just after deployment on SYS-123. NASA Photo.

The overall project has two key objectives: (i) basic research will extend our understanding of the materials/space environment interactions, and (ii) specific knowledge will be gained for critical materials in several on-going projects of the team members.

\section{Sample Panel Design}

The SUSpECS study will expose two test panels of materials to the LEO environment for $\sim 17$ months. Environmental monitoring on board the MISSE-6 suitcases will include temperature monitoring at a number of points on each pallet. Atomic oxygen (AO) exposure will be monitored by the degradation of Kapton strips placed on the pallet frames, with an estimated sensitivity of $\sim 25 \%$ AO variation [2], [3]. Solar ultraviolet (UV) exposure as a function of time will be monitored with UV photodiodes at several locations. Absolute absorbed radiation dosage will be monitored with several thermoluminescent detectors (TLD), as was done on MISSE-1 and -2. The Air Force MISSE-6 experiment will contain monitoring of the electron flux in the $0-200 \mathrm{eV}$ regime.

\section{A. Ram Side Sample Panel Configuration}

One SUSpECS sample panel will be mounted on the ram side of the ISS, with enhanced exposure to atomic oxygen. These experiments are all passive LEO exposure experiments. This panel will include $981.3 \mathrm{~cm}$ diameter ( $1 \mathrm{~cm}$ exposed diameter) conducting and insulating test samples held at ground potential, as shown in Figures 1(a-c). The specific samples are identified in Table I.

The ram-side sample holder is configured so that four stacked sample tiers will be exposed to AO+UV, AO alone ( 2 sets), and no AO or UV. All these materials will be tightly seated in a metal tray. The sample geometry is designed such that the sides of each tier will be masked allowing only front face exposure and forcing any diffusion into a one-dimensional regime. This will permit one-dimensional depth profiling of the materials to evaluate the effects of environmental exposure. The outermost tier will experience the fullest exposure to all of the variables of LEO environment, most importantly atomic oxygen and ultraviolet radiation. The lower tiers, being shielded by the outermost layer, will not have exposure to ultraviolet radiation. Due to a gap between the second and third tiers in the stacked configuration, the second and third tiers will have exposure to reduced fluxes of atomic oxygen. The lowest tier is fully shielded from ultraviolet radiation and atomic oxygen by the third tier. In addition to the MISSE6 onboard monitors of UV and AO flux, the cumulative fluence at various points on SUSpECS will also be monitored. AO exposure will be monitored by the relative oxidation of high purity Ag strips [2], [3], [4] and the degradation of Kapton strips [2], [3] placed on the frame of each tier. UV exposure will be monitored by the discoloration of $1.3 \mathrm{~cm}$ diameter, $1 \mathrm{~cm}$ thick borosilcate BK7 glass sample disks mounted on each tier as color centers are formed by the UV radiation. 


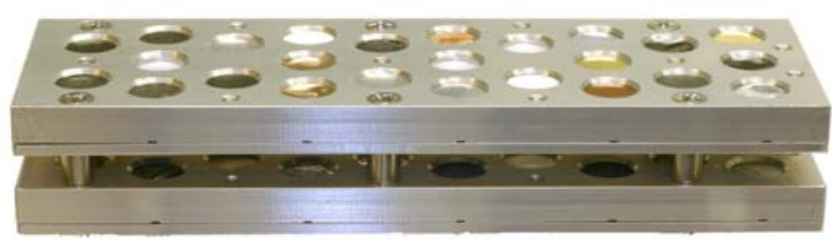

(a)

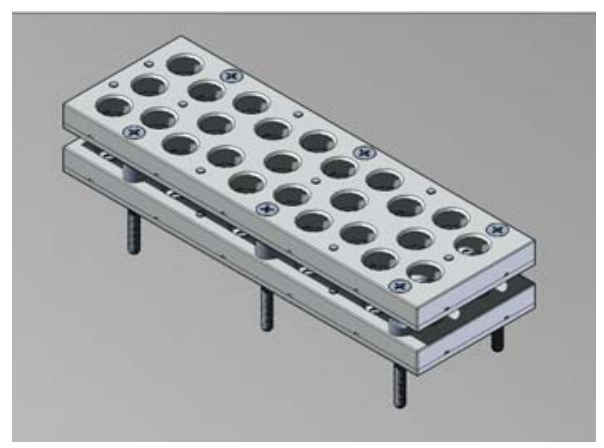

(b)

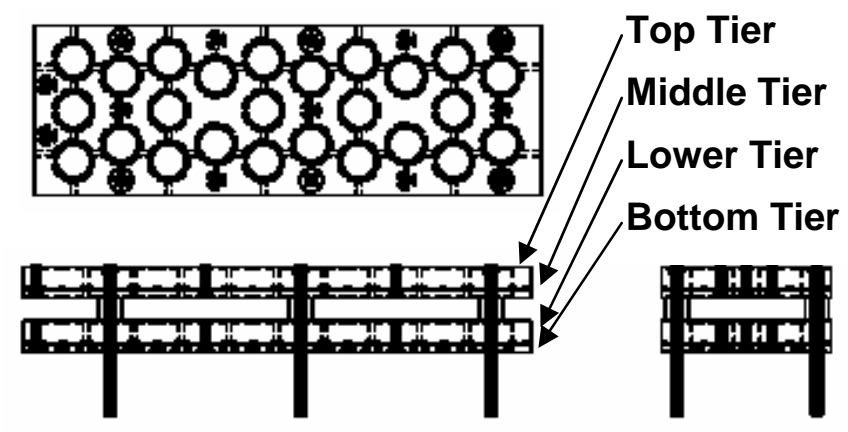

(c)

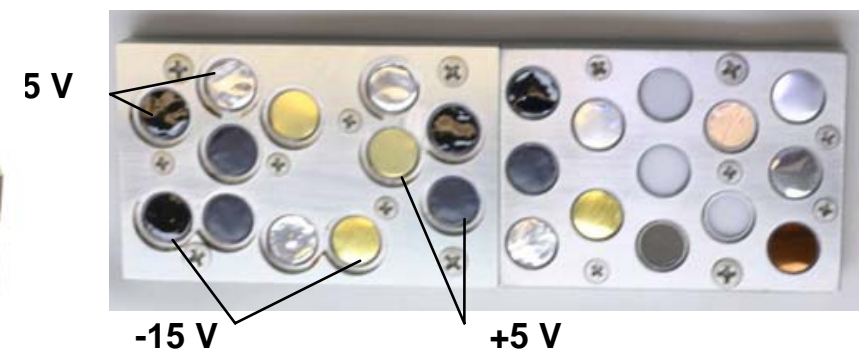

(d)

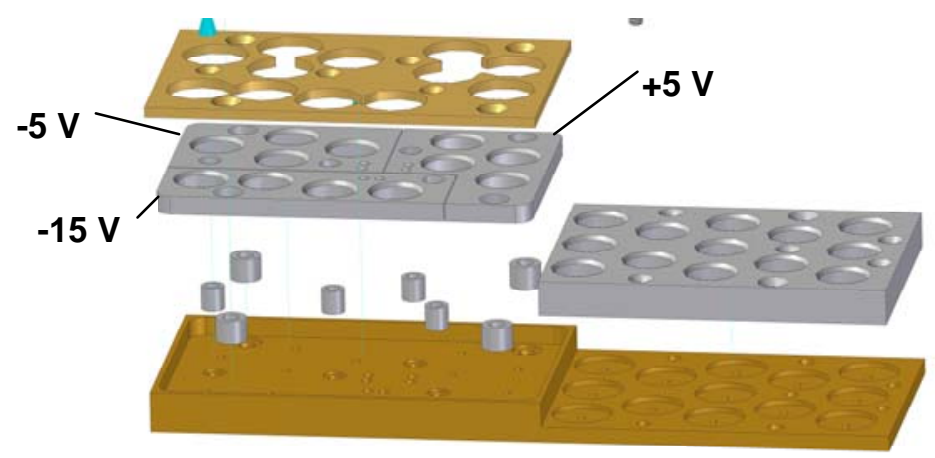

(e)

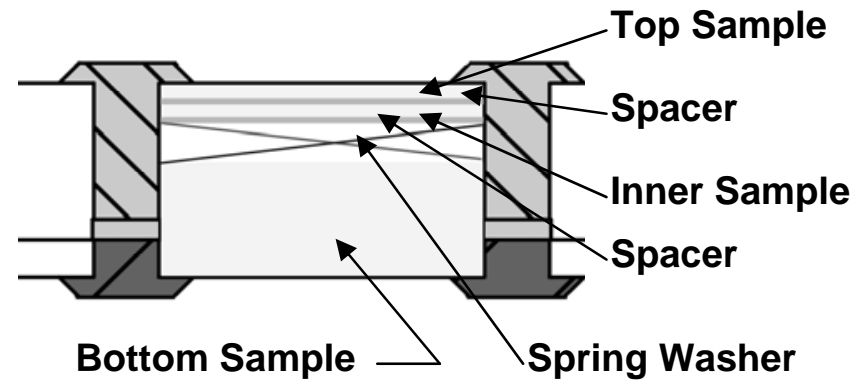

(f)

Figure 2. Configuration of $5 \mathrm{~cm}$ x $30 \mathrm{~cm}, 78 \mathrm{~cm} 2$ SUSpECS sample panels. (a-c) Ram side sample panels. All samples are passive experiments held at ground potential. A three tiered configuration design is used with 25 samples exposed on each tier. (d-e) Wake side sample panel. Thirteen exposed samples at right are passive experiments held at ground potential. The three sub-panels at left each contain four identical samples held at +5 VDC, -5 VDC and -15VDC, respectively. (f) Cross sectional detail of typical stacked samples and sample clampina mechanism.

\section{B. Wake Side Sample Panel Configuration}

The second SUSpECS sample panel will face the wake side of the ISS, with less exposure to atomic oxygen. The experiments are both passive and active LEO exposure experiments. This panel will include $131.3 \mathrm{~cm}$ diameter test samples held at ground, as shown in the right hand side of Figures 1(c-d). The specific samples are identified in Table I. Additional grounded samples are mounted underneath the exposed samples (see Table I).

There are also three separate test sub-panels of $\sim 13 \mathrm{~cm}^{2}$, each with four conducting samples ( $\mathrm{Au}$, Al, Dupont Black Kapton, and Sheldahl Thick Film Black) mounted, as shown at left in Figs. 1(c-d). These three sub-panels will be held at +5 VDC, -5 VDC and -15 VDC, respectively. Voltages for the sub-panels are provided by the ISS through the MISSE-6 bus. Current is drawn from interaction of the biased plates with the space plasma 
environment. Based on a plasma current density of $\sim 10 \mathrm{nA}-\mathrm{cm}^{-2}$, the three biased plates will collectively draw $<1 \mu \mathrm{A}$. Resistors and fuses (MIL-PRF-23419) to limit arcing currents are mounted in series with each sub-panel.

A grounded sample guard is positioned above the three sub-panels to minimize possible contact biased sub-panels by astronauts during EVAs. The beveled edges of the sample clamp and guard shield have been designed to minimize fringing fields and provide nearly parallel voltage contours typical of larger biased samples. A field profile simulation is shown in Figure 3.

The biased sample configuration is designed to approximate typical conditions of materials subject to spacecraft charging. The positive test bias was chosen as $+5 \mathrm{~V}$. Positively charged components will typically charged to only a few volts positive [5], since low energy emitted electrons will be reattracted to a positively charged surface and the majority of emitted electrons have energies below $\sim 5$ to $10 \mathrm{eV}$ [6]. By contrast, negatively charged materials can charge to large voltages, since emitted electrons are repelled from the charged surface and therefore do not self-limit charging, as is the case for positive biasing [6]. Biases of $-5 \mathrm{~V}$ and $-15 \mathrm{~V}$ were chosen as representative of modest and more extreme negative charging.

\section{Sample Selection Criteria}

The samples for flight have been carefully chosen to provide needed information for several different ongoing studies and to cover a broad crosssection of prototypical materials used on the exteriors of spacecrafts. Table I lists the samples selected for inclusion on the SUSpECS sample panels.

The majority of the test samples have already undergone pre-flight analysis during an ongoing seven year study of the electron emission [7-11] and resistivity properties [7], [12-15] of spacecraft materials sponsored by the NASA Space Environments and Effects Program. Preliminary

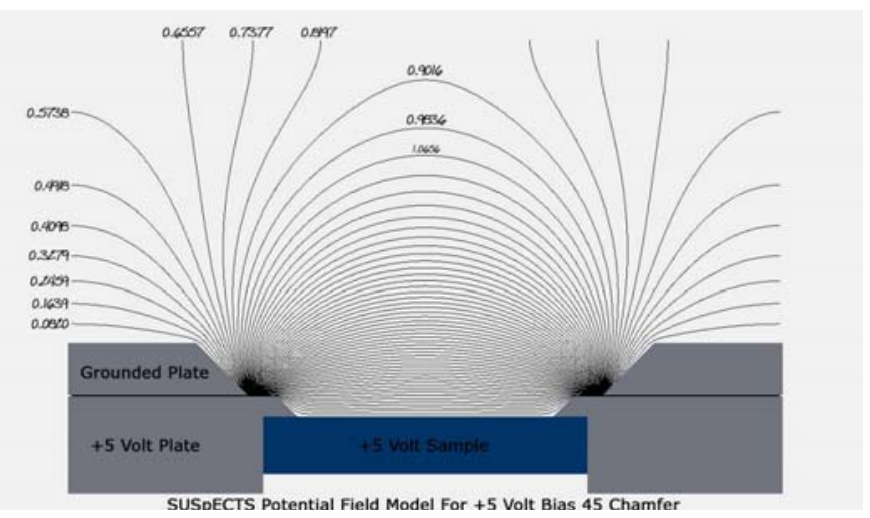

Figure 3. SimION simulation of the electrostatic potential contour lines for a +5 VDC sample bias.

Table I. SUSpECS Samples

\begin{tabular}{|c|c|c|}
\hline Material & Source & \#Samples \\
\hline Kapton (PI) on Aluminum & Sheldahl & 4 \\
\hline Teflon (PTFE) on Aluminum & Sheldahl & 3 \\
\hline Mylar (PET) on Aluminum & Sheldahl & 3 \\
\hline Nylon $6 / 6$ & McMaster-Carr & 1 \\
\hline SiO2 (Fused Quartz) & UQG Optics & 3 \\
\hline Al2O3 (Sapphire) & UQG Optics & 2 \\
\hline Germanium on Kapton & Sheldahl & 1 \\
\hline Anodized Aluminum (Chromic Acid Etch) & NASA / MSFC & 1 \\
\hline Anodized Aluminum (Sulfuric Acid Etch) & NASA / MSFC & 1 \\
\hline UV AR-coated Ce-doped Cover Glass & Thales & 3 \\
\hline FR4 Printed Circuit Board (PI Composite) & CRRES NASA / JPL & 3 \\
\hline CV-1147 RTV on Copper & Nusi/Boeing & 1 \\
\hline DC93-500 RTV on Copper & Dow-Corning/Boeing & 2 \\
\hline Zinc Oxide White Paint (Z93-C55) & Alion & 3 \\
\hline Borosilicate BK7 Glass & UQG Optics & 3 \\
\hline Gold (99.99\% Purity) & ESPI & 7 \\
\hline Aluminum ( $99.999 \%$ Purity) & ESPI & 7 \\
\hline 316 Stainless Steel & McMaster-Carr & 2 \\
\hline OFHC Copper ( $99.9 \%$ Purity) & McMaster-Carr & 1 \\
\hline Silver (99.999\% Purity) & United Materials & 3 \\
\hline g-C (Graphitic Amorphous Carbon) on Copper & Arizona Carbon Foil & 1 \\
\hline Aquadag (microcrystalline C) on Copper & LADD Research & 2 \\
\hline 100XC Black Kapton & Sheldahl & 6 \\
\hline Thick Film Black & Sheldahl & 6 \\
\hline Inconnel on Silver on Teflon on ITO & Sheldahl & 1 \\
\hline ITO on Teffion on Silver on Inconel & Sheldahl & 1 \\
\hline Gold (2um)/Nickel(2um) on 316 Stainless Steel & Gold Plating Services & 3 \\
\hline $\operatorname{Rh}(2 u m) / N i(2 u m)$ on 316 Stainless Steel & Gold Plating Services & 3 \\
\hline $\mathrm{Au}(2 \mathrm{um}) / \mathrm{Rh}(2 \mathrm{um})$ on 316 Stainless Steel & Gold Plating Services & 3 \\
\hline $\mathrm{Au}(2 \mathrm{um}) / \mathrm{Rh}(2 \mathrm{um}) / \mathrm{Ni}(2 \mathrm{um})$ on 316 Stainless Steel & Gold Plating Services & 3 \\
\hline Reinforced Carbon Nano-fiber/RS-3 Cyanate Ester Composite & SDL GIFTS Satellite & 2 \\
\hline ASN720 Oxide Ceramic-Metal Composite & COIC/ATK Thiokol & 5 \\
\hline S200 Nonoxide Ceramic-Metal Composite & COIC/ATK Thiokol & 5 \\
\hline Thiokol Graphite Epoxy Foil - No Hole & ATK Thiokol & 5 \\
\hline Thiokol Graphite Epoxy Foil - With Hole & ATK Thiokol & 5 \\
\hline Thiokol Carbon-Carbon Composite \#1 & ATK Thiokol & 5 \\
\hline Thiokol Carbon-Carbon Composite \#2 & ATK Thiokol & 5 \\
\hline Thiokol Fiber-Filled Carbon-Carbon Composite & ATK Thiokol & 5 \\
\hline Thiokol Carbon-Phenolic Carbon-Carbon Composite & ATK Thiokol & 5 \\
\hline S400 Nonoxide Ceramic-Metal Composite & COIC/ATK Thiokol & 2 \\
\hline S200H Nonoxide Ceramic-Metal Composite & COIC/ATK Thiokol & 2 \\
\hline S300 Nonoxide Ceramic-Metal Composite & COIC/ATK Thiokol & 2 \\
\hline
\end{tabular}
ground-based studies at USU have shown that contamination can produce dramatic changes in electron emission that can lead to severe charging effects under certain circumstances [16] A preliminary study of the effects of contamination of resistivity using the charge storage method is underway at USU. Comparison with post-flight analysis will provide the first extensive tests of space environment exposure and contamination on electron emission properties and resistivity.

Several types of samples were flown aboard the CRESS satellite [15] as part of a study of spacecraft charging induced arcing [17]. The samples have recently been subjected to detailed resistivty tests using the charge storage method [18] and very successful modeling of their pulsing history during the CRESS flight [12,19]. The MISSE-6 tests will be valuable in trying to model the effects of prolonged space exposure during the CRESS flight. Relevant samples include Kapton (PI), Teflon (PTFE), Mylar (PET), FR4 PC board (PI composite) material, Alumina $\left(\mathrm{Al}_{2} \mathrm{O}_{3}\right)$, and Silicon Dioxide $\left(\mathrm{SiO}_{2}\right)$.

A study of the electron emission and resistivity properties of a set of materials used to construct the ISS has been performed. This includes both basic materials [Au, Al, $316 \mathrm{SS}$, Anodized Al (Chromic acid etch), Anodized Al 
(Sulfuric acid etch), Kapton, Dupont Black Kapton, and UV AR-coated Ce-doped cover glass] [7] and a study of two RTV materials (DC93-500 and CV-1147) thought to be key contaminants of the ISS solar arrays [11]. Comparison of analysis of these MISSE-6 samples with pre-flight testing will provide valuable information for modeling the ISS spacecraft charging as the station ages.

A study of the electron emission and resistivity properties of a set of materials that were used to construct the Floating Potential Measurement Unit (FPMU) is currently underway. The FPMU is an instrument designed and built at SDL for use on the ISS [20], [21] intended to monitor spacecraft charging on the ISS [22-24] through plasma measurements. The sample set includes both basic materials used to construct the FPMU [Au, $316 \mathrm{SS}$, Aquadag] and two RTV materials (DC93-500 and CV-1147) thought to be potential key contaminants of the FPMU [7], [26]. The electron emission properties and resistivity of the materials, and how these properties change with exposure to the space environment and the accumulation of contamination, are critical to the precise determination of the surface potentials. Comparison of analysis of these MISSE-6 samples with pre-flight testing will provide valuable information for modeling the FPMU electron emission and the instrument effectiveness in monitoring the ISS potential as the station ages.

Stringent requirements for uniform work function of the FPMU probes led to coating key elements with Au [20]. Another critical concern is non-uniform modification of the Au work function due to external contamination or to diffusion of alloying materials from underlying layers into the $\mathrm{Au}$, particularly at elevated temperatures [25]. A set of samples [Au, $\mathrm{Au}(2 \mu \mathrm{m}) / \mathrm{Ni}(2 \mu \mathrm{m})$ on $316 \mathrm{SS}, \mathrm{Rh}(2 \mu \mathrm{m}) / \mathrm{Ni}(2 \mu \mathrm{m})$ on $316 \mathrm{SS}, \mathrm{Au}(2 \mu \mathrm{m}) / \mathrm{Rh}(2 \mu \mathrm{m})$ on $316 \mathrm{SS}$, $\mathrm{Au}(2 \mu \mathrm{m}) / \mathrm{Rh}(2 \mu \mathrm{m}) / \mathrm{Ni}(2 \mu \mathrm{m})$ on $316 \mathrm{SS}$ ] will be included in the unexposed samples on SUSpECS. Although these samples will not be exposed to the external space environment, they will experience prolonged exposure to the thermal and vacuum environment. Separate ground based experiments will look at the effects of proposed heating to clean the FPMU.

Tests will be performed to study aging and degradation phenomenology of critical thermal control and optical materials currently in use or under development for SDL payloads. These include the inorganic white and black polymeric coatings used for GIFTS composites.

Composite and ceramic materials of the ATK Thermal Protection Systems (TPS) and the ATK Lightweight Structure Systems (LSS) are used on LEO bound and beyond ATK assets. These include materials for an ATK Thiokol project on snap-together structural components and solid rocket motor materials. A set of these composite materials will be evaluated for deleterious effects of AO, UV and other space environment exposure. Some ATK composite rocket motor cases include epoxy resin. Two of these epoxy resin types will be included in this LEO exposure experiment. Composite materials to be tested include a graphite fiber-filled composite, a carbon-carbon resin-impregnated graphite composite, a carbon-phenolic composite, and an anodized aluminum metal-coated composite. The proprietary ATK COI ceramic matrix composite (CMC) materials will be tested in an oxide form and a polymer derived non-oxide form.

The Health Management Focus Group (HMFG) of ATK Space Systems will perform material characterization as a function of time and/or environment using the proven ATK HMFG microspecimen technology tools for chemical and mechanical property analysis. Studies of the service life of these materials will evaluate chemical and mechanical properties of the ATK MISSE samples. Triplicate samples will be evaluated for each material: one for zero-time properties, one for ground-based aged properties, and one for space exposure. Thiokol samples will be subjected to mechanical tests, including destructive mechanical tests, microwave evaluations of changes in the relative dielectric function, and ultrasonic measurements. In addition, a series of microtome slices of the pertinent composite samples will be made to evaluate chemical and mechanical properties as a function of depth from the AO and UV exposure surface. Chemical analysis, including ATR and/or diffusive reflection spectroscopy, Auger, SIMS, XPS spectroscopies, and standard chemical suite of tests as applicable will also be performed on all microtome samples.

ATK Space Systems has worked on a series of programs during the past few years that dramatically improved our ability to assess the effects of aging based on fundamental science rather than the empirical approaches that have dominated the past. Significant progress has been made in the union of high fidelity data sources and high fidelity structural, damage, and failure models. The results of SUSPECS will provide much needed input data for these models as the ATK HMFG assesses the effects of exposure to the environment of LEO on these materials.

\section{Testing}

\section{A. Materials Testing}

Comparison of post-flight analysis of these MISSE-6 samples with pre-flight testing will be valuable in trying to identify and model materials degradation and aging and the effects of prolonged space exposure on the samples. All 
samples will undergo an extensive series of pre-flight and post-flight tests to characterize the materials including surface morphology tests [optical microscopy, scanning electron microscopy (SEM), scanning tunneling microscopy (STM)], chemical compositions tests, [standard suite of chemical analysis tests such as HPLC, Auger Electron Spectroscopy (AES), Secondary Ionization Mass Spectroscopy (SIMS) and X-Ray Photoelectron Spectroscopy (XPS)], optical tests (IR-VIS-UV attenuated total (ATR), specular and/or diffuse reflection spectroscopy), thermal tests (thermal expansion, thermal emissivity and absorptivity), and outgassing. Outgassing tests and some optical and morphology tests will be performed at SDL; other characterization will be done at Thiokol.

The electron emission properties and resistivity of most USU/SDL materials will be tested. Specifically, the materials will be tested for resistivity and dielectric strength, and for electron-, ion- and photon-induced electron emission yield curves and emission spectra. Details of the testing procedures are described in [7]. Much of the preflight testing has already been done in conjunction with previous studies.

\section{Electrical Properties of Spacecraft Materials}

A primary focus of SUSPECS is the study the effects of contamination on the accumulation, re-emission, and dissipation of charge from spacecraft surfaces and on the resulting changes in electron emission and resistivity of spacecraft materials. This project also investigates on the effects of charging on contamination rates. Synergistic phenomena in the space environment (e.g., charging, contamination, UV exposure, atomic oxygen) can cause dramatic changes in material surface properties and performance [27]. Thin contaminant layers readily change the optical [28] and electronic properties [16,29] of surfaces, and often result in long-term degradation of the optical, thermal control, or electronic performance of space based sensors and components. For example, plasma diagnostic instrumentation (such as Langmuir and plasma impedance probes) requires stable surface conductivity and charging properties, which is altered by contamination [25]. Further, at geosynchronous orbits, high spacecraft charging potentials (typically tens of kilovolts) and long Debye lengths can actually accelerate surface contamination rates by electrostatic re-attraction of ionized outgassed or vented molecules to the negatively charged satellite [30]. The accelerated contamination rates can affect the long-term performance of optical, thermal control, or solar panel surfaces. Also, at all altitudes, the performance of new high efficiency multijunction solar cells is more susceptible to current loss caused by contamination than conventional single junction cells [31].

The electron emission and transport properties of materials are key parameters in determining the likelihood of deleterious spacecraft charging effects [5], [7], [32], [33] and are essential in modeling these effects with engineering tools such as the NASA NASCAP-2K code [34], [35]. The SUSpECS studies of electron emission and resistivity will extend more than a decade of research in the field by the USU Materials Physics Group [7-14], [16], [18], [25], [27]. Preliminary ground-based studies have shown that contamination can lead to catastrophic charging effects under certain circumstances [16]. However, little direct information is available on the effects of sample deterioration and contamination on the electron emission and resistivity of materials flown in space.

Recent work [13], [36] has found that dissipation of charge accumulated on thin film insulating spacecraft surfaces during on-orbit conditions is substantially slower than predicted using resistivity values acquired by standard ASTM methods [37]. Under many typical conditions this can result in charge dissipation on the order of days to months rather than minutes to hours [12]. More appropriate methods to measure charge storage decay have been developed. An apparatus to measure the decay rate of charge deposited on the surface of thin film insulators has been designed and built at USU in conjunction with an on-going NASA research project with JPL [14]. Comparison of pre- and post-flight analysis of SUSpECS samples using these methods will provide a better understanding of modifications to these long decay times as a result of space exposure and contamination

\section{Acknowledgments}

We gratefully acknowledge the Air Force Office of Scientific Research (AFOSR) that sponsors the MISSE program and NASA that provides transportation to and from the ISS aboard the Space Shuttle. Gary Pippin, Steve Hahn, and the team at Boeing have provided invaluable support for the project and will work with the NASA Langley Research Center to integrate the SUSpECS sample panels into the MISSE-6 Passive Experiment Containers (PECs) for transport to the ISS. We also have profited from useful discussion with M.R. Carruth, Jr. and T. Schneider at NASA Marshal Space Flight Center and John Alred at Boeing about ISS materials; Charles Swenson in the Electrical and Computer Engineering Department at USU about FPMU materials; Clint Thompson and Jim Burns at ATK Space Systems; and A. Robb Frederickson and Nelson W. Green at the Jet Propulsion Laboratory about CRRES materials. Andrew Auman performed the SimION electric field simulations. Sarah Barton, Jodie Corbridge Guthrie, Ryan Hoffmann and Jonathan Abbott of the USU Department helped with various 
characterization measurements and sample preparation. Jim Dyer at USU Space Dynamics Laboratory was instrumental in characterization measurements and sample preparation and assembly.

\section{References}

1 “Material International Space Station Experiment (MISSE),” http://misse1.larc.nasa.gov/ ,March 24, 2005.

2 J.J. Osborne, I.L. Harris, G.T. Roberts and A.R. Chambers, Satellite and Rocket-borne Atomic Oxygen Sensor Techniques," Rev. Sci. Instrum., 72(11), 4025-4041, 2001.

${ }^{3}$ Steven L. Koontz, Lubert L. Leger, Steven L. Rickman, Charles L. Hakes, David T. Bui, Donald E. Hunton and Jon B. Cross, " Oxygen Interactions with Materials III-Mission and Induced Environments," J. Spacecraft Rockets, 32(3), 475-482, 1995.

${ }^{4}$ Peter Joseph Codella, The Oxidation of Silver Thin films by Atomic Oxygen, PhD Dissertation, Utah State University, Logan, UT, 1977.

${ }^{5}$ D. Hastings, and H. Garrett, Spacecraft-environment Interactions, Cambridge University Press, 1996.

${ }^{6}$ N. Nickles, R.E. Davies, J.R. Dennison, "Applications of Secondary Electron Energy- and Angular-Distributions to Spacecraft Charging," Proc. of the 8th Spacecraft Charging Tech. Conf., (AFRL Sc. Center, Hanscom AFB, MA, USA), 2000.

7 J.R. Dennison, C.D. Thomson, J. Kite, V. Zavyalov and, Jodie Corbridge, "Materials Characterization at Utah State University: Facilities and Knowledgebase of Electronic Properties of Materials Applicable to Spacecraft Charging," Proceedings of the $8^{\text {th }}$ Spacecraft Charging Technology Conference, (NASA Marshall Space Flight Center, Huntsville, Al, October 2003).

${ }^{8}$ JR Dennison, W.-Y. Chang, Neal Nickles, Jason Kite, C.D. Thomson, Jodie Corbridge and Carl Ellsworth, Final Report Part II1: Materials Reports, NASA Space Environments and Effects Program Grant, "Electronic Properties of Materials with Application to Spacecraft Charging," September 2002. Published by NASA electronically at http://see.msfc.nasa.gov/scck/, the work is comprised of 16 individual Materials Reports.

9 JR Dennison, C. D. Thomson, and Alec Sim, "The effect of low energy electron and UV/VIS radiation aging on the electron emission properties and breakdown of thin-film dielectrics," Proceedings of the $8^{\text {th }}$ IEEE Dielectrics and Electrical Insulation Society (DEIS) International Conference on Solid Dielectrics (ICSD), 967-971, (IEEE, Piscataway, NJ, 2004.

${ }^{10}$ C.D. Thomson, V. Zavyalov, and J.R. Dennison, "Instrumentation for Studies of Electron Emission and Charging from Insulators," Proceedings of the $8^{\text {th }}$ Spacecraft Charging Technology Conference, (NASA Marshall Space Flight Center, Huntsville, Al, October 2003).

${ }^{11}$ C.D. Thomson, V. Zavyalov, J.R. Dennison and Jodie Corbridge, "Electron Emission Properties of Insulator Materials Pertinent to the International Space Station," Proceedings of the $8^{\text {th }}$ Spacecraft Charging Technology Conference, (NASA Marshall Space Flight Center, Huntsville, Al, October 2003).

12 J.R. Dennison, A.R. Frederickson and Prasanna Swaminathan, "Charge Storage, Conductivity and Charge Profiles of Insulators As Related to Spacecraft Charging," Proceedings of the $8^{\text {th }}$ Spacecraft Charging Technology Conference, (NASA Marshall Space Flight Center, Huntsville, Al, October 2003).

13 A.R. Frederickson and J.R. Dennison, "Measurement of Conductivity and Charge Storage in Insulators Related to Spacecraft Charging," IEEE Transaction on Nuclear Science, 50(6), 2284-2291 (December 2003

${ }^{14}$ Prasanna Swaminathan, A.R. Frederickson, J.R. Dennison, Alec Sim, Jerilyn Brunson and Eric Crapo, "Comparison of Classical and Charge Storage Methods for Determining Conductivity of Thin Film Insulators," Proceedings of the $8^{\text {th }}$ Spacecraft Charging Technology Conference, (NASA Marshall Space Flight Center, Huntsville, Al, October 2003).

${ }^{15}$ E. Mullen and M. Gussenhoven, "Results of Space Experiments: CRRES," in R.N. DeWitt, D. Duston, and A.K. Hyder (eds.) The Behavior of Systems in the Space Environment, pp. 605-654, (Kluwer Academic Publishers, 1993).

${ }^{16}$ R.E. Davies and J.R. Dennison, "Evolution of Secondary Electron Emission Characteristics of Spacecraft Surfaces," J. Spacecraft and Rockets, 34, 571-574 (1997).

${ }^{17}$ A.R. Frederickson, E.G. Mullen, K.J. Kerns and P.A. Robinson, "The CRRES IDM Spacecraft Experiment for Insulator Discharge Pulses,” IEEE Trans. Nuc. Phys. 40(2), 233-241 (1993). ).

${ }^{18}$ Nelson W. Green, A. Robb Frederickson and J.R. Dennison, "Charge Storage Measurements of Resistivity for Dielectric Samples from the CRRES Internal Discharge Monitor," Proceedings of the $9^{\text {th }}$ Spacecraft Charging Technology Conference, (EPOCHAL TSUKUBA, TSUKUBA, April 4-8, 2005).

${ }^{19}$ A. R. Frederickson and Donald H. Brautigam, "Mining CRRES IDM Pulse Data and CRRES Environmental Data to Improve Spacecraft Charging/Discharging Models and Guidelines," Final Report: NASA SEE Program Contract No. NAS71407, Task Order 10676, 2003(b); to be published.

${ }^{20}$ Charles M, Swenson, Barjatya, A., Thompson, D., Fish, C, "Calibrating the Floating Potential Measurement Unit," Proceedings of the $8^{\text {th }}$ Spacecraft Charging Technology Conference, (NASA Marshall Space Flight Center, Huntsville, Al, October 2003).

${ }^{21}$ C. Swenson, D. Thompson, C. Fish, The Floating Potential Measurement Unit, number AIAA-2003-1081 in 41st aerospace Sciences Meeting and Exhibit, January 2003.

${ }^{22}$ Dale C. Ferguson, David B. Snyder, Ralph Carruth, Report of the Joint Workshop of the Space Station Freedom Plasma Interactions and Effects Working Group, the Space Station Freedom Plasma Working Group, and the Space Station Freedom EMI/EMC and Electromagnetic Effects Working Group, 1990. 
${ }^{23}$ Steve Koontz, Marybeth Edeen, William Spetch, Thomas Keeping, Penni Dalton, Assessment and Control of Spacecraft Charging Risks on the International Space Station, Proceedings of the $8^{\text {th }}$ Spacecraft Charging Technology Conference, (NASA Marshall Space Flight Center, Huntsville, Al, October 2003).

${ }^{24}$ M.R. Carruth Jr., T. Schneider, M. McCollum, M. Finckenor, R. Suggs, D. Ferguson, I. Katz, R. Mikatarian, J. Alred, and C. Pankop, "ISS and space environment interactions without operating plasma contactor," AIAA Paper \#2001-0401, Proc. of the 39th AIAA Aerospace Sci. Meeting, Reno, Nevada, Jan. 8-11, 2001.

${ }^{25}$ L. Gamble, J. R. Dennison, B. Wood, J. Herrick, and J. S. Dyer; "Calculation of Spectral Degradation due to Contaminant Films on Infrared and Optical Sensors," Proc. SPIE-The International Society of Optical Engineering, Vol. 4774, p. 111-118, Optical System Contamination: Effects, Measurements, and Control VII, Philip T. Chen; O. Manuel Uy; Eds. (2002).

${ }^{26}$ M.R. Carruth, Todd Schneider, Matt McCollum, Miria Finckenor, Rob Suggs, Dale Ferguson, Ira Katz, R. Mikatarian, John Alred, H. Barsamian, J. Kern, S. Koontz, and J.F. Roussel, Plasma Charging of the International Space Station. IAS paper IAC-02-T.2.05, 2002.

${ }^{27}$ D.C. Marvin, T.B. Stewart, G.S. Arnold, D.F. Hall, R.C. Young Owl, W.C. Hwang, and H.D. Marten, , "Photochemical Spacecraft Self-Contamination: Laboratory Results and Systems Impacts," J. Spacecraft and Rockets, Vol. 26, p. 358-367 (1989).

${ }^{28}$ B. E. Wood, W. T. Bertrand, R. J. Bryson, B. L. Seiber, P. M. Balco, and R. A. Cull, "Surface Effects of Satellite Material Outgassing Products," Journal of Thermophysics and Heat Transfer, 2 (4), pp. 289-295, 1988.

${ }^{29}$ W.Y. Chang, J.R. Dennison, Jason Kite and R.E. Davies, "Effects of Evolving Surface Contamination on Spacecraft Charging," Proceedings of the $38^{\text {th }}$ American Institute of Aeronautics and Astronomics Meeting on Aerospace Sciences, (Reno, NV, 2000).

${ }^{30}$ P.D. Thomas, Michael C. Fong, and K.L. Neir, "Return Flux of Neutral and Charged Particles in Geosynchronous Orbit", Proc. SPIE-The International Society of Optical Engineering, Vol. 3427, p. 290-301, Optical System Contamination: Effects, Measurements, and Control, Philip T. Chen; William E. McClintock, Gary J. Rottman; Eds. (1998).

${ }^{31}$ D.F. Hall and D.C. Marvin, "Effects of Molecular Contamination on Triple Junction Solar Cells," Proc. SPIE-The International Society of Optical Engineering, Vol. 4774, p. 129-134, Optical System Contamination: Effects, Measurements, and Control VII, Philip T. Chen; O. Manuel Uy; Eds. (2002).

${ }^{32}$ K.L. Bedingfield, R.D. Leach and M.B. Alexander,: "Spacecraft System Failures and Anomalies Attributed to the Natural Space Environment.” NASA Reference Publication 1390, NASA MSFC, 1996.

33 R.D. Leach, and M.B. Alexander: "Failures and Anomalies Attributed to Spacecraft Charging," NASA Reference Publication 1354, NASA Marshall Space Flight Center, November 1994.

${ }^{34}$ M.J. Mandell, P.R. Stannard and I. Katz, "NASCAP Programmer's Reference Manual,” NASA LRC, 1993.

${ }^{35}$ M. Mandell, "NASCAP-2K - An Overview"," Proceedings of the $8^{\text {th }}$ Spacecraft Charging Technology Conference, (NASA Marshall Space Flight Center, Huntsville, Al, October 2003).

${ }^{36}$ A.R. Frederickson, C. E. Benson and J. F. Bockman, "Measurement of Charge Storage and Leakage in Polyimides," Nuclear Instruments and Methods in Physics Research B, 454-60, 2003.

${ }^{37}$ ASTM D 257-99, "Standard Test Methods for DC Resistance or Conductance of Insulating Materials,” (1999). 